10 Keith A A study of hospital outpatient and emersency depurtment sericess Backsround puper 10. Melbourne: National Health Strategv, 1992.

1 National Health Strategy. The Australian health jigsaze integration of health care deliverv. Issues paper 1. Melbourne: National Health Strategy, 1991

12 National Health Strategy. Hospital services in Australia access and financing. Issues paper 2. Melbourne: National Health Strategy, 1991.

13 National Health Strategy. The future of general practice. Issues paper 3. Melbourne: National Health Strategy, 1992
14 National Health Strategs. Issues in drug use in Australiu. Issues puper 4 . Melbourne: National Health Strategy, 1992

15 Better Health Commission. Looking foresard to hetter health. Iols I and 2. Canberra: Australian Government Publishing Service, 1986

16 Health Targets and Implementation (Health for All) Committee. Health for all A ustralians. Report to Australian health ministers. Canberra: Australian Government Publishing Service, 1988.

17 Gray G. Federalism and health policy: the dezelopment of health svstems in Canada and Australia. Toronto: University of Toronto Press, 199

\title{
Drugs and exercise testing
}

\author{
Consider the reason for the test
}

"Should I take my tablets before the test?"- a common question, but what should be the response in the context of exercise testing and coronary artery disease? Many drugs may substantially affect a patient's exercise capacity, and antianginal drugs in particular may influence many end points assessed during exercise testing. Despite this no consensus exists on whether exercise testing should be performed in the presence or absence of drugs. ${ }^{12}$

Several studies have confirmed the exercise test as a valuable tool in the assessment and prognosis of coronary stenosis. ${ }^{3}$ Although antianginal treatment increases exercise tolerance and decreases symptoms, few data exist on whether it modifies the risk of myocardial infarction in patients with chronic stable angina. The importance of "silent ischaemia" is much debated, but exercise induced ST changes without symptoms are no longer considered to be grounds for therapeutic complacency. ${ }^{+}$It could be argued that all patients should be exercised first off drugs to objectively assess symptoms and risk and then again when they are symptomatically stable on drugs. Patients should then be referred for further investigation on the basis of the first exercise test, with the urgency of referral being based on the second test.

The original studies of the prospective value of exercise testing in chronic stable angina did not exclude patients treated with $\beta$ blockers; the results were valid irrespective of $\beta$ blocker use. $\beta$ Blockers reduce mortality after myocardial infarction, but the use of exercise testing to establish prognosis after myocardial infarction was investigated largely in the absence of $\beta$ blockade. Such treatment might be expected to increase the sensitivity of exercise testing (the probability of a positive test result in those patients with a positive diagnosis) but to decrease its specificity (the probability of a negative test result in those patients with a negative diagnosis). Furthermore, the prognostic implication of a positive exercise test result rendered negative by drug treatment is unknown, ${ }^{\gamma}$ although better short term outcome was noted in a preliminary study of patients in whom these changes were found on exercise radionuclide ventriculography. ${ }^{8}$

In exercise tests used to investigate chest pain the diagnostic yield will be greatest without the confounding effects of antianginal drugs, which should be stopped at least five half lives before the test. For patients presenting with angina who are already taking drugs a baseline test during treatment will go some way toward identifying those at highest risk, while repeating the test off treatment in those who originally tested negative may establish the usefulness of the electrocardiographic aspect of the exercise test in further follow up. Testing the response to specific treatments (for example, angioplasty) should be performed under stable therapeutic conditions. Exercise testing to establish prognosis after myocardial infarction is best undertaken in the absence of calcium antagonists and nitrates. Whether $\beta$ blockade alters the prognostic reliability of a negative result remains unknown, and long term trials are needed. ${ }^{9}$
The withdrawal of drugs causes much concern. If patients experience frequent exertional angina then an exercise test is unlikely to yield further diagnostic information. These patients require further investigation, the urgency of which may be assessed by an exercise test on drugs if the angina is infrequent. Antihypertensive drugs complicate the situation because of their antianginal effects - a positive test result on drugs provides useful information, but a negative result does not, particularly if accompanied by repolarisation abnormalities in the resting electrocardiogram. Other drugs, including digoxin, flecainide, and amiodarone, may interfere with the electrocardiographic interpretation of an exercise test (particularly the lateral ST segments, which are notoriously labile in the presence of digoxin). "Therapeutic difficulty" should be considered an indication for early catheterisation.

Regardless of the problems caused by antianginal drugs in interpreting results of exercise tests, the limitations of these tests in coronary artery disease in general should not be forgotten. Even in patients with clinically important disease up to one in five tests may yield negative results. Exercise testing identifies fixed high grade stenoses, but the risk of infarction is also a function of the number of stenoses, regardless of severity. In common with coronary angiography, exercise testing produces little information about the stability of atheromatous plaque: substantial numbers of patients develop coronary thrombosis with stenosis of less than $50 \%$.

Exercise tests should be requested and interpreted in the light of these limitations if scarce resources are to be used most effectively.

TERRI MILLANE Cardiology Registrar

DAVID WARD

Regional Cardiothoracic Unit, Consultant Cardiologist

St George's Hospital, London SW17 9QT

1 Lim R, Dymond D). Viewpoint: Should antianginal medication be stopped before exercise testing? Lancet 1992;340: 161-2.

Muir KW, Rodger JC, De Bono JS, McDonald H, Irving JD. Drugs and the exercise test. B.M. 1992;305:808-9.

3 Schlant R, Blomquist C, Brandenburg R, DeBusk R, Ellestad MH, Fletcher (GF. Guidelines for exercise testing. A report of the joint American College of Cardiology/American Hear Association task force in assessment of cardiovascular procedures (subcommittee on exercise testing). Circulation 1986;74:653-67 A.

+ Nyman I, Larsson H, Areskog M, Wallentin L. The predictive value of silent ischemia at an exercise test before discharge after an apisode of unstable coronary artery disease. RISC Sudy Group Am Hearl 7 1992:123:32t-31.

5 MeNeer F, Margolis J, Lee K, Kisslo JA, Peter RH, Kong Y. The role of the exercise test in the evaluation of patients for ischemic heart disease. Circulation 1978;57:64-70.

6 Weiner D, Rvan T, McCabe C, Chaitman BR, Sheffield LT, Ferguson JC. Prognestic importance of a clinical profile and exercise test in medically treated patients with coronary artery disease. of a clinical profile and exercise

Murray D, Tan L, Salih M, Weissberg P, Murray R. Does beta adrenergic hlockade influence the prognostic implications of post-myccardial infarction exercise testing? Br Heart 7 1988;60:47+-9. Lim R, Dyke L, Dymond D. Effect on prognosis of abolition of exercise-induced painles myocardial ischemia by medical therapy. Am $\mathcal{F}$ Cardiol 1992;69:733-5.

9 Curtis G, Houghton J, Patterson J, Koch H, Bradley D, Adams K Jr. Propranolol therapy alter estimation of potentional cardiovascular risk derived from sub-maximal exercise testing Am Heart 7 1991;121:1655-8.

10 Moos A, Prevedel J, Mohiuddin S, Hilleman D, Sketch M Sr. Effect of digoxin on ST-segmen changes detected by ambulatory electrocardiographic monitoring in healthy subject. Am y Cardiol 1991;68:1503-6. 